\title{
LEVEL CROSSING SAFETY IN THE CZECH REPUBLIC
}

\author{
Martin KobosiL*, Jan NovÁK \\ CTU in Prague, Department of Forensic Experts in Transportation, Horská 3, 12803 Prague 2, Czech Republic \\ * corresponding author: kobosmar@fd.cvut.cz
}

\begin{abstract}
This paper describes safety threats at level crossings according to the different type of security equipment. Initially were explored statistical data, which consist of numbers of level crossings classified by crossing type and numbers of traffic accidents on level crossings. Afterwards paper describes specific problems of each individual level crossing type. Specifically their causation and consequences, which are being discussed between professional and general public. In conclusion paper describes possible solutions to these problems leading to reducing risks at level crossings. At first is mentioned the statistics - number of crossing and number of accidents on the crossing. Then paper describes specific problems, which are discussed in professional and general public. They are also solutions of this problems, which brings another point of view and search the actual causes.
\end{abstract}

KEYwORDS: railway, level crossing, active safety, visibility splays .

\section{LEVEL CROSSINGS SAFETY IN NUMBERS}

We can classify railway level crossing according to the different type of security equipment. On the 31th December 2016 was in the Czech Republic total number of 7,961 level crossings. 3,938 of them was equipped only with warning cross (W. Cross). On these 49.5 percent of all level crossings it depends only on driver's decision whether he will enter crossing or not. This decision is based on the level of an attention, driver's experiences and especially on visibility splays. Remaining 4,023 level crossings was secured by on type of an active security equipment. 2,356 of which was equipped with warning lights (W. Lights), 1,310 level crossings was equipped with warning lights accompanied by automatic barriers (W. Lights with A.B.) and 326 level crossings was equipped with mechanically operated barriers (Mech. O.B.). The last 31 level crossings had some other form of protection [1].

\subsection{LEVEL CROSSINGS ACCIDENTS}

Rules about how to behave on level crossings are well known. They have been established by the law, taught in driving schools and presented in mass media and in primary schools. Theoretically, if these rules would be obeyed, there should be no extraordinary incidents. Therefore from legal point of view are traffic accidents on level crossings in majority of cases caused by driver. However in terms of prevention it is essential to examine other consequences and to investigate what factors led to the breaking the law. Number of traffic accidents on level crossings according to type of security equipment is shown in Table 1.

\subsection{Specific issues of EACH TYPe OF SECURITY EQUIPMENT}

Each type of above mentioned security equipment is different and has typical safety problems. The

\begin{tabular}{llll}
\hline Security Equipment & Accidents & Killed & Injur. \\
\hline W. Cross & 67 & 4 & 27 \\
\hline W. Lights & 85 & 25 & 49 \\
\hline W. Lights with A.B. & 27 & 14 & 3 \\
\hline Mech. O.B. & 1 & 0 & 1 \\
\hline Total & $\mathbf{1 8 0}$ & $\mathbf{4 3}$ & $\mathbf{8 0}$ \\
\hline
\end{tabular}

TABle 1. Number of Traffic Accidents on Level Crossings According to the Type of Security Equipment (2014) [2].

vast majority of these issues is linked to active safety. When we will solve them, we will significantly decrease the number of traffic accidents on level crossings and decrease the economic loss from traffic accidents. According to the Rail Safety Inspection in 2013 there was a loss of 37.5 million Czech crowns on railway vehicles, 3.7 million crowns on infrastructure and 19.0 million crowns on other participants involved in traffic accidents. To these figures have to be also added society-wide losses from injuries and deaths [2].

\section{LEVEL CROSSINGS EQUIPPED WITH WARNING CROSS}

Main cause of problems on level crossings equipped only by warning cross are undoubtedly visibility splays, which are very often insufficient. Owner of the railway has legal obligation to carry out regular maintenance of vegetation and to remove any other obstructions, which negatively impacts on visibility splays. In particular circumstances, where this cannot be achieved, i.e. due to the difficult ground conditions or due to land ownership disputes, it should be installed signalling equipment ideally in combination with crossing barriers. 


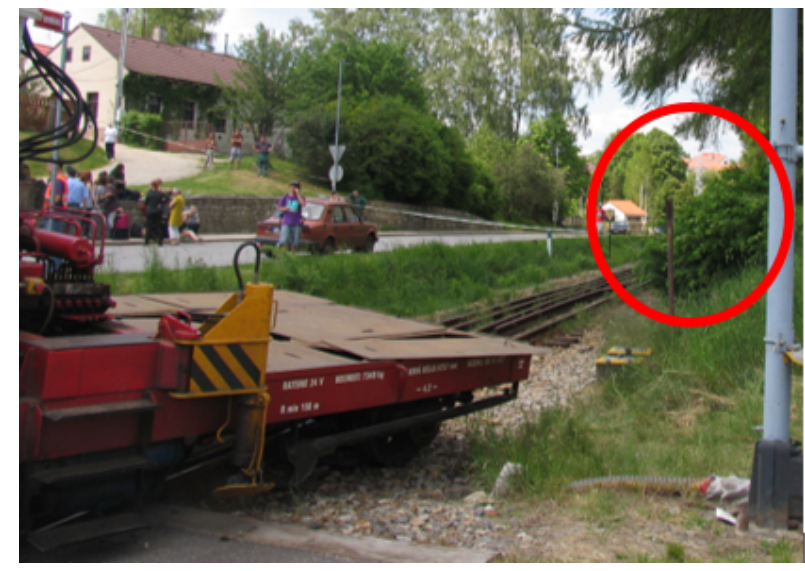

FiguRE 1. Vegetation Intruding Visibility Splays on Level Crossing (source Police Czech Republic).

Visibility splays are defined in design standard CSN 736380 , which is legally binding on the basis of regulation No. 177/1995 Sb. This standard explains how to correctly determine visibility splays, however it has one issue. According to the Paragraph No. 88 of this regulation, above mentioned standard CSN 736380 is not binding for level crossings, which project documentation was approved before this standard came into effect. Vast majority of railway was designed and built in the end of the 19th century and in the first half of the 20th century. Visibility splays on these older railways are defined by internal regulation of a railway operator SZDC S 4/3. Calculations are in the principle similar to methods used in design standards and are based on physical principles, however in the end of the regulation $\mathrm{S} 4 / 3$ it is allowed to reduce visibility splays by half. This statement is based on the theory of probability and enables to reduce visibility splays in the case of a low probability of a collision, which implies on level crossings with low operational speed on the line along with low traffic volumes. However with this statement cannot be agreed either from the scientific view or from the human view. It is essential to respect physical laws and give driver enough time to decision, reaction and for safe crossing of a level crossing [3, 4.

Another problem might be complete overlooking of a level crossing, which comprise of two inconspicuous rail tracks across the road. Drivers are notified about presence of a level crossing by three traffic signs A31 complemented by warning cross sign A32, but these are only traffic signs, which is nothing unusual in road traffic and can be overlooked. Other vulnerable group are drivers, which are familiar with level crossing, but can simply forget about its presence as well as they forget they are daily driving around memorial.

Solution to this problem has to be something, which is not as common as traffic signs and should be on the road, where driver is concentrating his attention. Road markings could be applied as an optical psychological brake V18. In technical specifications TP 65 "Traffic signs manual" is about traffic sign V5 quoted
"Additionally it is used on intersection to mark out where vehicle has to stop to give way, in front of the controlled pedestrian crossing and alternatively also in front of the level crossing" [5].

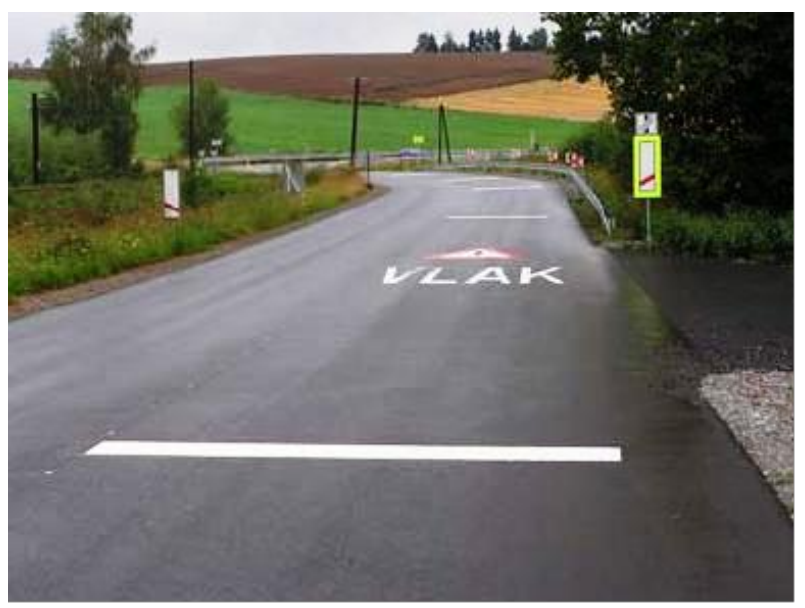

Figure 2. Level Crossing Highlighted by Optical Psychological Brake V18 (source Mr Sachl).

\section{LEVEL CROSSINGS EQUIPPED WITH WARNING LIGHTS}

Severity of traffic accidents on these level crossings is highest from all of the level crossing types due to the higher operational speed on the line. Reasons for disrespecting rules on these level crossings can be overlooking of red warning lights or driver's risky behaviour. Visibility splays on these level crossings does not have to be large, because they are used only when security equipment is out of service.

Basic rule of this security equipment says: "Do not enter the level crossing, when the red light is flashing." But what is the reason for disobeying this rule? In mass media the reason is often attributed to the aggressive and undisciplined drivers, but the truth could be somewhere else. Hardly will anybody drive in front of the moving train because of the curiosity 'if I will make it' or because of the desire for adrenaline.

First problem could be visibility of the warning lights, which does not comply with the selfexplanatory principle. Especially dangerous are level crossings in urban areas, where buildings, foliage, traffic signs or other structures are forming longitudinal lines, which may cause overlooking of a warning lights. In this case it is appropriate to mark and highlight transverse lines by using road markings or 'lights bar', which is placed on the road as can be seen on Figure 3. However it is important to keep in mind that every level crossing has to be assessed individually and that solution of this problem requires cooperation of the railway operator and road maintenance provider.

Second problem with higher level of risk are drivers, which deliberately enters level crossing despite flashing warning lights. This phenomenon can be seen especially at small cities and villages, where local residents 


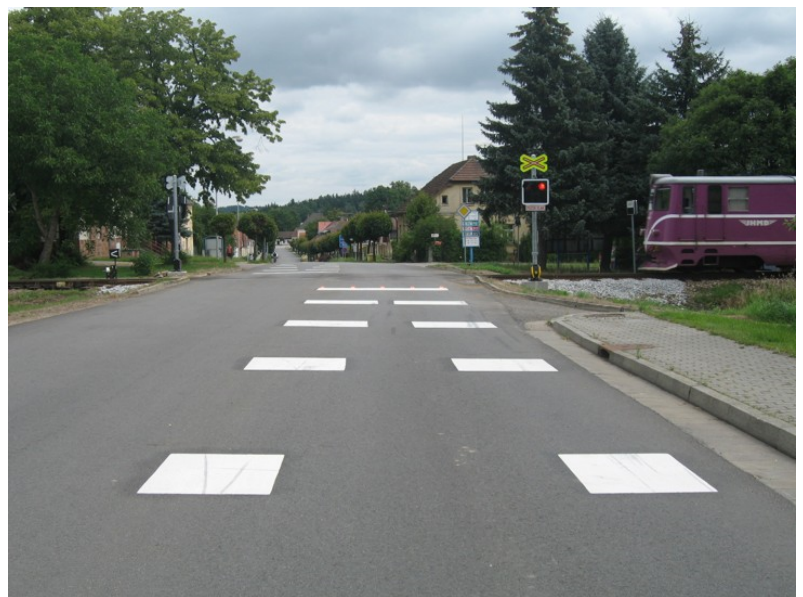

Figure 3. Level Crossing Highlighted by 'light bar' and Optical Psychological Brake (source Mr Skladany).

knows, that it usually takes a long time before the train approaches level crossing after the warning light came on. This situation is particularly dangerous for the next people in a row, because human psychology works like 'He made it, so will I'. These people enter the level crossing following the example they have seen and tragedy is near.

Another problem, which is typical on level crossings oriented to the west or to the east is also sun and its glare. The intensity of warning lights on these crossings should be increased, e.g. by the use of a LED technology.

\section{LEVEL CROSSINGS EQUIPPED WITH WARNING LIGHTS ACCOMPANIED BY AUTOMATIC BARRIERS}

This is the safest and the most advanced type of level crossing safety equipment. The barriers are lowered across the road, which makes it clear, that it is forbidden to enter the crossing. On these level crossings is caused only a small number of traffic accidents, but when an accident happens it has usually greater consequences. Typical and almost only threat on this type of security equipment is called 'S-manoeuvre' between the half-barriers as shown on Figure 4. These drivers are the biggest gamblers with their lifes. From this reason are some level crossings being equipped with enforcement video cameras, which can record and penalise hazardous drivers [6].

Second cause of dangerous situation is when driver is closed between the safety barriers. But this mistake does not have to be fatal. First option is that second passenger can raise the barrier or the barrier can be lifted up by the bonnet of a car. Barriers are intentionally balanced, that only a minimal strength is required to raise them. Second option is breaking the barrier with a car. Every barrier is designed to be easily broken by impacting on it in horizontal direction. It is necessary to raise public awareness about

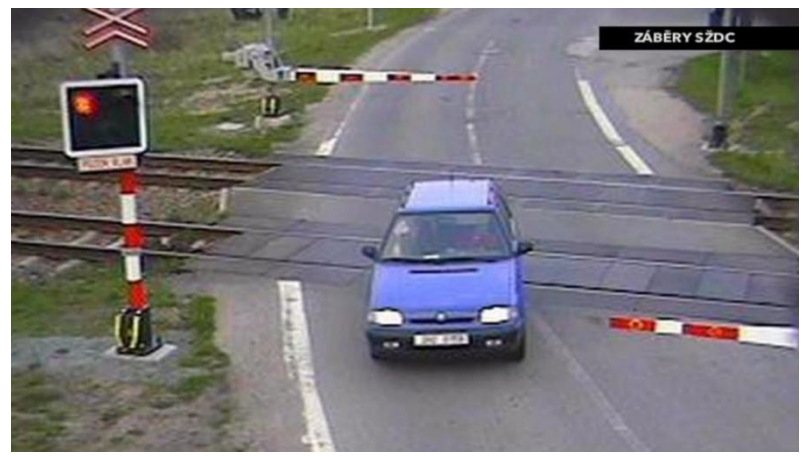

Figure 4. S-manoeuvre 6].

this subject and to spread these information between road users. This pack of information is necessary to get to the subconscious mind of general public by enlightenment.

The another solution consists of installing detection devices, which can detect trapped vehicle on level crossing. This device send information about trapped car and can give appropriate command to warn or to stop approaching train. The main technical problem of this solution is reliability of the vehicle recognition. Low reliability can cause many false alarms and many delays of trains. These detecting systems are already successfully used abroad.

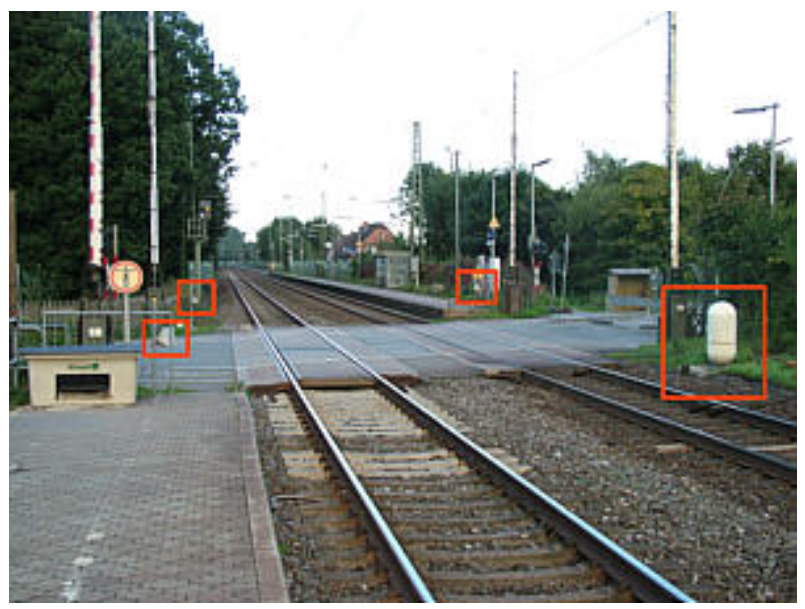

Figure 5. Level Crossing with Vehicular Detectors [7.

\section{HOW TO REDUCE RISK ON LEVEL CROSSINGS}

We can hear from mass media and between professional and general public that it is drivers who makes mistakes on level crossings. This statements is generally correct, because majority of collisions between motor vehicles and railway vehicles has origin in driver errors, but often as an originator of traffic accidents is considered aggressive behaviour of drivers. It is true that many drivers are speeding, tailgating or making other traffic offences, however on level crossings it is usually simple human errors. Driver is concentrating on the road in front of him, but on the road he sees 
only two inconspicuous lines across the road. Just after double swing of a vehicle he realizes it was rail tracks. By lucky chance it ends up with wiping sweat from a forehead, sometimes it ends up tragically.

For effective reducing traffic accident numbers on level crossings it is necessary to change an approach in assessing the whole issue and to focus on genuine causes of traffic accidents. It is essential to make every inconspicuous or hazardous level crossing visible. Police has to focus on dangerous evading crossing barriers. Additionally it is necessary to shut down duplicate level crossings and level crossings with low usage, to build grade separated railway crossings and to take care of visibility splays by maintaining vegetation and removing other obstructions. Equally important is raising of public awareness in driving schools and through mass media and various campaigns of safety organisations.

\section{REFERENCES}

[1] Zeleznicni prejezdy v cislech, cit 2017-02-10. Operator of the Track SZDC [online], http://www.szdc.cz/web/ prejezdy/prejezdy-v-cislech.html

[2] Statistika nehodovosti na zeleznicnich prejezdech, 2015. The Rail Safety Inspection Office.

[3] Csn 736380 zeleznicni prejezdy a prechody, 2014. Czech Technical standad.

[4] S 4/3 - internal regulation, 2014. Operator of the Track SZDC.

[5] Tp 65 "traffic signs manual", 2013. Technical Manual.

[6] Zeleznicni prejezdy budou hlidat kamery, cit 2017-02-10. Czech Television [online], http://www . ceskatelevize.cz/zpravodajstvi-ostrava/zpravy/ 204475-zeleznicni-prejezdy-budou-hlidat-kamery/ 1

[7] I. R. P. .-. [online]. Ieee railway projects 2015-2016, cit 2017-02-10. http:

//ieeerailwayprojects2015-2016.blogspot.cz/ 